\title{
APPARATUS FOR DETERMINING THE REFRACTION OF WATER.
}

\author{
By P. G. Agnew, \\ Pontiac, Mich.
}

It seems to be always allowable to suggest another modification of the usual method of determining the index of refraction of water by means of the conventional rectangular glass jar.

In the form here shown in oblique projection, (scale $1-3$ ), the protractor is pasted on the outside of the jar, as usual, but facing inward. Transverse lines drawn on a sheet of white celluloid $C$ serve as a source of light. Angles in the water are read by sighting along three lines at the protractor. Angles in the air are read by stretching a fine black thread $t t$ across the top of the jar and so placing the threadand the eye of the observer that one of the lines, the center of the protractor, the thread, and the eye all lie in the same plane. The

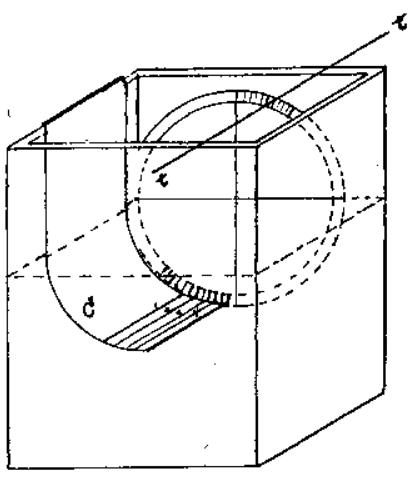
intersection of the plane with protractor gives the angle.

The celluloid strip is shaped by placing in hot water, bending to the desired form, and allowing to cool. Better definition of the center of the protractor is secured by pricking a pin-hole through the paper and placing that side of the jar toward the window by which the room is lighted.

Careful manipulation will bring the maximum error of a single determination to less than 2 per cent., provided only angles of more than to degrees are used.

\section{ON SCIENCE TEACHING. IV.}

By C. R. ManN.

Ryerson Laboratory, University of Chicago.

In the preceding articles some of the general ideas which bear directly on science teaching have been considered. The remaining ones will be devoted to more practical questions. We shall direct our attention to the problem of determining how the science teacher may best prepare himself to carry out the principles out- 
lined; for the question, "What can I do to strengthen my teaching and make it more vital?" must have occurred frequently to every earnest instructor.

I shall not attempt to give a categorical or ex cathedra answer to this question. Nor do I claim to be able to indicate more than the outlines of the solution of the problem for all the various branches of science. All that I can do is to call attention to some of the ideas that have helped me in making my instruction in physics more real and more interesting to my own students. I cannot but think, however, that these same ideas will be of assistance to those who are teaching sciences other than physics, if they will ponder them carefully, and apply them with such modifications as may in each special case be necessary.

The ideas to which attention will be directed are not new. They have been repeatedly emphasized and expounded by those who have written concerning the problem before us. I shall therefore indicate their sources and urge all teachers to study them in greater detail in the books in which they are set forth. The great and crying need of science teaching seems to be the practical application of these principles to actual instruction, and this each teacher must do for himself.

Perhaps the most important thing for every teacher to realize is the fact that no one can do good and really hearty work unless he has a clear and definite conception of the purpose or end towards which he is striving. Exactly what are you trying to accomplish by your labors? This is the great and central problem; for when a conscious aim has been developed in a teacher's mind, the battle is three-quarters won.

It is further clear that the quality of the purpose determines the quality of the instruction; for is not this a universal principle? Does not a conscious purpose precede every conscious act? And is not the quality of the act determined finally by the purpose that fathered it and whose expression the act is? Hence the conscious purpose of our instruction is the vital thing, and we should spare no pains or labor until we are sure that we have not only acquired one, but also assured ourselves that it is the best that can be acquired.

This purpose is also clearly a personal possession, which must inevitably be different, at any rate in detail, for each individual. For his teaching is part and parcel of the teacher's acts, and hence his purpose in it must bear the stamp of his individuality 
perhaps even more markedly than do the purposes that impel him to his other actions. And if the purposes that lead a number of people to each do the same act are all different, as they surely are, we must recognize at once that it is not possible to state the purpose of science teaching in a way that will appeal to all science teachers as the complete and only one. Furthermore, every one who appreciates this fact has thereby laid on him the responsibility of forming his own purpose. $\mathrm{He}$ should also realize that in this matter his responsibility is great, since the results of his teaching depend on it; and these results may mean inspiration or despair, quickened thought and imagination or deadened aspiration, a joyful and optimistic or a querrulous and pessimistic attitude toward life for those growing personalities entrusted to his care.

When a teacher once comes to realize the importance and the potency for good or evil of his teaching purpose, he surely will not rest until he has made a careful and thorough study of the present bearings of his particular subject in the world of thought, of its relations to other subjects, of its development in the life of his race, and of the present day attitude toward it. All this may necessitate much reading, and even more thinking on the part of the teacher; but if he is in earnest, the result will justify the labor and his reward will be great. He will find that such study as this bears a far richer harvest than the continued picking away in the deep dark mine of his specialty; for it brings him into touch with the rest of the world and leads him out where he can feel the throbbing warmth of the life about him. He will be cured of that mental rheumatism which is so powerfully depicted by Goethe in his Faust, and which makes him cold, cynical, and out of touch with his time.

The science teacher is particularly qualified to form such a living teaching purpose, because his training tells him how to go about it. $\mathrm{He}$ is familiar with the scientific method of thought, and so knows where to begin. His first step should be to inform himself as to what has already been done in this matter. What ideas of the purpose of science teaching have been advanced?

In The Teaching of Physics in the Secondary Schools, by Prof. E. H. Hall, we read, in the chapter on Physics in the Various Kinds of Secondary Schools (page 327): "On the subject of this chapter we have something approaching the authority of official utterance in the various publications made by the $\mathrm{Na}$ - 
tional Educational Association during the past ten or twelve years." Then follows portions of a report of a committee on College Entrance Requirements in Physics which was presented in I899. After outlining the essentials of the course proposed, the purpose of the work is stated as follows: "To the end that the pupil may gain not merely empirical knowledge, but, so far as this may be practicable, a comprehensive and connected view of the most important facts and laws in elementary physics." This then is the official utterance of the National Educational Association-the aim of teaching physics is to give the student as far as may be practicable a comprehensive and connected view of facts and laws.

That there are, however, those who question the finality of this official and authoritative utterance, we are told on page 337 of the same book. For it seems that a course in secondary physics has been organized in Brookline, Mass., whose purposes are: "I. To develop in the pupil the habit of steady, persistent, logical thinking; 2. To render him fairly intelligent in reference to his scientific environment; 3. To beget a sense of power in his own ability to appreciate scientific truth and to draw legitimate conclusions from simple data; 4. To teach him to apply the elements of algebra and geometry to the problems of daily life; and finally, 5. To arouse in him a deep sense of appreciation of all that modern science has done and is still doing for the comfort and convenience of the race."

Another point of view is taken by Karl Pearson in his Grammar of Science. This author believes that the claims of science for public support and a place in the school curriculum are four. The first is: "That science, as training the mind to an exact and impartial anlysis of facts, is an education specially fitted to promote sound citizenship." The second is that science increases our knowledge and understanding of the laws of Nature and society. Since method and knowledge are both essential to sound judgment in civil and social life, science is practically valuable in proportion as it furnishes these two elements in 'education. But in the third place, "Pure science has a further strong claim on us on account of the exercise it gives to the imaginative faculties and the gratification it provides for the æthetic judgment." And finally, "Its last great claim to our support is the capacity it has for satisfying our cravings for a brief description of the history of the world." The science teacher in search of his pur- 
pose should not fail to read carefully at least the first few chapters of this Grammar of Science.

One of the best and most useful monographs on the subject is the little book by Mrs. M. E. Boole, entitled, The Preparation of the Child for Science. This book pleads with teachers to recognize the fundamental distinction between the ways of teaching science and those of teaching languages. It is a simple yet powerful argument for guarding the freedom of the child's individual judgment. Thus we read (page 22) : "In classical learning it is eminently desirable to secure that the right impression shall be made from the first; that the the wrong impressions shall have as little time as possible to deepen themselves. We wish the child's eye and ear to become accustomed from the first to welcome the right and reject the wrong; we do not wish him to gain any habit of tolerating wrong impressions. If the child uses the nominative where he should use the accusative, and is not at once corrected, that is so much to the bad for his future progress; if he can be got not to be able to remember a time when he used the word wrongly, that is so much to the good. But in science there are, there can be, no absolutely right impressions; our minds are not big enough to grasp any natural fact as a whole; everything depends on drawing right conclusions from combinations of impressions, each of which is in itself inadequate and partially misleading; and if the pupil is to be got into scientific methods, that is what he must be trained to do." And on page 26 , "What science does claim is, that no child shall be told anything about the motion of the earth till he has observed many sunrises and sunsets; till a clear sense-impression of the earth standing still and the sun moving has become organic within him. This registering of a 'wrong' impression is what in science we have to secure; while in the classics we should try to prevent it." Further, page 32, "But when a child has formed for himself a clear, undisturbed impression of the earth's unmovableness and the apparent motion of the sun, and then has read that astronomers believe the earth goes round and the sun does not go round the earth, if he then puts together in his mind the two apparently conflicting statements and lets them combine to create in him an impression which shall embrace both, then the sacrosanct scientific act has taken place in his mind. He has really done a bit of true science work."

This book is full of excellent irleas. Note also the following: 
"Scientific education is not arrived at, and never can be arrived at, by young people being crammed at school and college with ready-made knowledge; and left to find out, after adult life and its duties have come on them, that they are still very ignorant of how to learn what they now need to know. Nor do they mend the matter then, by turning in disgusted recoil from the sham knowledge with which others crammed them, to cram themselves from books, with ready-made theories about the limits of the knowable and the philosophy of the unknowable. Scientific culture is the result of a steady, life-long habit of friendly and intimate, though reverent, intercourse with the Eternally Infinite Unknown."

Still another valuable book on this subject is Education and the Larger Life, by $\mathrm{C}$. $\mathrm{H}$. Henderson. We are here told that the development of human power should be the aim of all education. We are reminded that great mental ability or a well-stocked memory does not atone for physical weakness. The physicist reads with interest his remarks about our proneness to overlook physical defects in our pride over our scientific achievements. Thus: "Our eyes are near-sighted and astigmatic and we can hardly recognize our friends across the street; yet with our telescopes we can study the details of the moon. Our voices are weak and squeaky; yet with the long-distance telephone we can shout the prices of corn from New York to Chicago. Even Stentor could not do that. The average man is short-winded and weakkneed; yet the trolley car rushes him to his office, and the limited whisks him across the country." Every teacher will find much in this book to inspire and strengthen his work.

This subject is well nigh inexhaustible. There are many, many other works that bear in whole or in part on it. Three others should without fail be studied before forming a final teaching purpose. These are Froebel's Education of Man, Miss Blow's Symbolic Education, and Hanus's Eduactional Aims and Educational Values. All of these are so well known that they need no introduction.

The preface of almost every text-book on your subject contains some ideas bearing on this problem. Further, membership in an association of science teachers where such topics are discussed cannot but help in building up a strong teaching purpose. But the teacher must not forget that it is his privilege and his duty to form his own purpose for himself. A ready-made, stock- 
in-trade purpose is a blind that does more harm than good. Unless his purpose bears the stamp of the teacher's individuality, it is not vital; he will not work enthusiastically toward its attainment. This finding of one's individual purpose may require considerable time, for it is impossible to reach the goal without much contemplation and careful thinking. Yet it is not time to realize that without deep thought the possibility of a comprehensive science does not exist; a wholly practical knowledge, directed entirely to facts and industrial pursuits, is, after all, of exceedingly little importance in the development of the human soul-a development which it is the teacher's highest duty to foster and encourage?

\section{THE DEFINITION OF A LIMIT.}

\section{By Ernest B. Lytle, University of Illinois.}

In the article entitled "Limits in Geometric Forms," in the October number of School Science and Mathematics, the author is unfortunate in selecting a bad definition of a limit and consequently fails to see that the limit of a variable is an intrinsic property of the variable. Further, he magnifies the importance of the limit of a geometric form when the elementary teacher should be chiefly concerned about limits of variable numbers. We believe such an article to be of little benefit, if not actually injurious, to the teacher of elementary mathematics for whom it was written, because its wrong point of view leads to hazy notions of limits.

The definition of the limit of a variable number is of fundamental importance in the calculus, the theory of infinite series and the theory of functions. So important a definition should be clear, definite and simple as possible. In this article we purpose to show why the definition of a limit given in the above mentioned article is bad and to give a better definition; to show that the limit of a variable number depends only upon the definition of the variable and is an intrinsic property of the variable, and to show why the limits of geometric forms are of little importance, if not dangerous, to the teacher of elementary mathematics.

The definition of the above mentioned article is as follows: "A limit is that constant value (or form) which a variable value (or form) approaches indefinitely near but never quite reaches." 